\title{
Truncamento no português brasileiro: para uma melhor compreensão do fenômeno ${ }^{1}$
}

\author{
Truncation in Brazilian Portuguese: for a better \\ understanding of this phenomenon
}

\author{
Ana Carolina Vilela \\ Universidade Federal de Minas Gerais \\ Luisa Godoy \\ Universidade Federal de Minas Gerais \\ Thaïs Cristófaro Silva \\ Universidade Federal de Minas Gerais²
}

\begin{abstract}
This article evaluates and discusses cases of truncation in Brazilian Portuguese (BP). A general evaluation of truncated forms in BP is presented within traditional grammatical approaches, and we also consider some proposals presented in manuals of morphology. Finally, we consider some articles that focus on theoretical issues related to truncation. In order to have a better understanding of truncation in $\mathrm{BP}$ we organized an experiment to evaluate over a hundred truncated forms. Results from our experiment indicate that truncated forms tend to follow general patterns, although such patterns are not categorical. We also distinguish truncated forms from cases of reduction of lexical items. Our results offer insights for future analyses on truncation and reduced forms in BP and may also contribute to the discussion of the interaction between phonology and morphology.
\end{abstract}




\section{Key words}

Truncation, Phonology, Morphology, Brazilian Portuguese, Lexicon

\section{Resumo}

Este artigo discute o tratamento apresentado na literatura lingüística para casos de truncamento no português brasileiro. O truncamento é um fenômeno de encurtamento de palavras, que gera formas de até no máximo três sílabas, tais como cerva (< cerveja), facú (< faculdade) e vestiba (< vestibular), usadas como substitutas de suas respectivas palavras-matriz. Avaliamos o tratamento oferecido nas gramáticas tradicionais, nos manuais de morfologia de língua portuguesa e em abordagens específicas (ARAÚJO, 2002, GONÇALVES, 1999). Enquanto as gramáticas e os manuais descrevem o fenômeno como aleatório e assistemático, os lingüistas GONÇALVES e ARAÚJO propõem análises inovadoras, tecendo generalizações que evidenciam a sistematicidade do processo de truncamento. Entretanto, como ambos os autores dispõem de poucos dados, as generalizações que apresentam não podem ser tomadas como categóricas. A partir da coleta e organização de um corpus relativamente extenso (em torno de 150 vocábulos), testamos as assertivas dos autores, listando as características do truncamento, as quais se configuraram mais como tendências do que como regras categóricas. Com essa listagem, pudemos, ainda, diferenciar os processos de truncamento e redução vocabular, muitas vezes analisados como idênticos.

\section{Palavras-chave}

Truncamento, Fonologia, Morfologia, Português brasileiro, Léxico 


\section{INTRODUÇÃO}

$\mathrm{E}$ ste artigo avalia um fenômeno observado no português brasileiro (PB) contemporâneo que altera a organização segmental de palavras já existentes. Alguns exemplos de vocábulos afetados por tal processo são: cerveja, que passa a coocorrer com cerva; deprimido, que dá origem a deprê; vestibular, que gera vestiba, entre outros. Uma pesquisa na literatura nos mostrou que há poucos trabalhos centrados nesse fenômeno - o qual denominaremos truncamento - e que os autores divergem quanto à conceituação e à nomenclatura, ora misturando processos distintos, ora baseando-se em poucos dados para construir suas generalizações. Nosso objetivo é, portanto, contribuir para o estudo do truncamento no PB e oferecer uma descrição mais refinada desse processo. Para isto, contamos com o suporte de um corpus específico coletado pelas autoras deste trabalho, o qual conta com dados análogos àqueles apresentados na literatura consultada e, adicionalmente, apresenta dados atestados na fala espontânea da comunidade de fala estudada.

Na seção 1, avaliamos o tratamento oferecido pelas abordagens tradicionais e discutimos alguns problemas presentes nelas. Na seção 2, apresentamos as propostas de Gonçalves (1999) e Araújo (2002), apontando as inovações que elas trazem. Na seção 3, discutimos dados de um experimento que realizamos, com o objetivo de avaliar empiricamente o comportamento das palavras truncadas no PB contemporâneo. Na seção 4, avaliamos as propostas de Gonçalves (1999) e Araújo (2002), oferecendo indícios para uma descrição mais apurada do fenômeno. Na seção 5, as generalizações de Araújo (2002) são discutidas à luz do nosso corpus. A seção 6 trata da distinção entre os processos de truncamento e redução vocabular, e a conclusão explicita os pontos mais relevantes deste artigo. 


\section{O FENÔMENO DO TRUNCAMENTO: ABORDAGENS TRADICIONAIS}

Esta seção discute a abordagem tradicional do truncamento, na qual ele é visto como fenômeno aleatório e assistemático.

\subsection{As gramáticas tradicionais}

Nas gramáticas tradicionais, não há uma delimitação precisa do que seja o truncamento tampouco critérios para distinguir esse fenômeno de outros semelhantes a ele. O que encontramos, em geral, é uma lista de dados e uma denominação para eles, sem análise aprofundada. Além disso, não há consenso entre os gramáticos em relação às classificações sugeridas. Tanto Bechara (2001) quanto Cunha \& Cintra (1985), por exemplo, chamam de abreviação formas como extra, de extraordinário ou extrafino, e auto, de automóvel. No entanto, a leitura de siglas (como em $O N U$ ) é, para o primeiro autor, um caso especial de abreviação e, para Cunha \& Cintra, um processo à parte. Cegalla (1991) denomina redução qualquer processo de encurtamento vocabular. Assim, dentro do conjunto das reduções, misturam-se indistintamente formas como foto, de fotografia, e Zé, de José. Luft (1996) lista diversos casos de truncamento bastante coloquiais (como purfa, de porfora, e burga, de burguês), e os classifica juntamente com reduções do tipo moto e quilo, como exemplos de derivação regressiva. Temos então que as propostas das gramáticas tradicionais podem ser refinadas em busca de uma melhor configuração dos fenômenos analisados. Na próxima subseção, avaliamos como o truncamentoé tratado em abordagens lingüísticas.

\subsection{A abordagem dos manuais de morfologia}

As análises lingüísticas dos manuais de morfologia são mais criteriosas em suas classificações do que as propostas apresentadas pelas gramáticas tradicionais. Contudo, ainda tratam o truncamento como um fenômeno aleatório e assistemático. Basílio (1991), por 
exemplo, chama de redução ou abreviação o processo de encurtamento de palavras e afirma que, nesses casos, "temos uma palavra formada pela supressão de alguma parte da palavra derivante" e que "a parte a ser suprimida é, muitas vezes, imprevisível”. A autora diz ainda que a palavra formada é sinônima da matriz, "apenas sendo usada, as mais das vezes, num estilo mais coloquial."

Já Sandmann (1992) distingue dois tipos de abreviação: (a) o das palavras do tipo cerva e (b) o das palavras do tipo máxi. No primeiro grupo, o processo se caracteriza "pelo aspecto de, às vezes, levar-se em conta uma suposta estrutura morfológica da palavra complexa". É o caso de cerveja que, sincronicamente, não apresenta mais de um morfema. Desta forma, a abreviação para cervaé, segundo o autor, arbitrária. No entanto, ele reconhece que há casos nesse grupo em que não se leva em conta a estrutura complexa da palavra (Exs.: grã-fino > granfa; Florianópolis > Floripa). Nessa classe, inserem-se ainda os apelidos (Exs: Lu, Cris, Jô, etc.), empregados em contextos menos formais. Já no segundo grupo, a estrutura da palavra complexa é levada em consideração, como em máxi, que pode vir tanto de maxidesvalorização quanto de maxissaia. Nesses casos, em que há duas palavras-matriz, o sentido é recuperado dentro do contexto.

Rocha (1999), por sua vez, classifica o processo como uma forma de derivação que pode ser de dois tipos: (a) a derivação truncada estrutural, em que se dá a eliminação de um elemento estrutural da palavra, como um sufixo ou uma das bases da composição (Exs: português > portuga; odontologia > odonto) e (b) a derivação truncada não-estrutural, em que o corte é aleatório e não leva em conta a estrutura da palavra (Exs: cerveja > cerva; São Paulo > Sampa; pneumático $>$ pneu). Ao final de sua análise, o autor questiona se o mecanismo lingüístico do truncamento "constitui de fato um processo de formação de palavras, nos moldes da derivação sufixal, por exemplo, em que se pode constatar a existência de RFP's" (Regras de Formação de Palavras). Caso positivo, isso daria ao truncamento as características de previsibilidade e sistematização. Contudo, nenhuma generalização nesse sentido é apresentada pelo autor. 
Novamente observamos a necessidade de uma caracterização mais precisa de fenômenos de natureza semelhante. A próxima subseção avalia alguns problemas inerentes às análises apresentadas.

\subsection{Problemas com a abordagem tradicional}

Com relação à abordagem tradicional, cabe aqui uma observação de teor metodológico. Na maioria das gramáticas e manuais de morfologia consultados, observamos a não-distinção entre os processos de truncamento, redução vocabular, abreviação e siglagem. A falta de critérios para separar os referidos processos acaba por gerar análises equivocadas.

O fenômeno da redução, por exemplo, é sempre inserido no mesmo grupo dos truncamentos. A nosso ver, formas como moto, químio e vice possuem características que as diferem de formas como granfa, Sampa e falsi. Neste artigo, chamaremos as primeiras de redução vocabular, separando-as do grupo dos truncamentos, como mostraremos na seção 6.

Tomemos, agora, a palavra apê. A maioria dos autores consultados lista o verbete juntamente com outros exemplos de truncamento. No entanto, apê não passa da representação ortográfica da matriz fonética da abreviação do vocábulo apartamento (ap.). Não deve ser, portanto, um caso de truncamento e, sim, de abreviação. Esse processo igualmente ocorre com Band (Bandeirantes).

As siglas também são, por vezes, confundidas com truncamentos. É o caso de tevê (leitura da sigla TV), que aparece listada ao lado de formas como foto e biju em alguns manuais. Tevê, no entanto, é formada a partir de um processo específico e muito produtivo no PB: a siglagem. Trata-se de um fenômeno muito diferente do truncamento, da redução vocabular e da abreviação. Neste artigo, entretanto, não nos ocuparemos dos processos de siglagem e abreviação. Para um maior detalhamento acerca do primeiro processo, indicamos a leitura de Gonçalves (1999). 


\section{UM NOVO OLHAR SOBRE O FENÔMENO DO TRUNCAMENTO: A SISTEMATICIDADE}

Mostraremos, a seguir, dois estudos inovadores, que propõem análises refinadas do truncamento e o analisam como um fenômeno sistemático. A seção 2.1 considera a abordagem sugerida por Gonçalves (1999), e a seção 2.2 considera o tratamento oferecido por Araújo (2002).

\subsection{A abordagem de Gonçalves (1999)}

Gonçalves (1999) sugere uma tipologia para o que chama de "processos não-concatenativos" do PB - reduplicação, truncamento, hipocorização, mesclagem lexical e siglagem -, tentando estabelecer os padrões de formação de cada um deles. Esses processos são, segundo o autor, operações morfofonológicas, pois operam ao mesmo tempo na morfologia e na fonologia da palavra. Daí a ineficiência de analisar os referidos processos por um prisma puramente morfológico, o que acabaria por levar o pesquisador a caracterizá-los como assistemáticos. Sobre o truncamento, especificamente, Gonçalves (1999) estabelece os seguintes critérios, buscando mostrar sua sistematicidade:

(1) (a) O truncamento é um recurso morfológico de natureza expressiva. Assim, não há diferença de significado entre a forma reduzida e a palavra-matriz; o que há é a utilização da forma truncada para a expressão de um tipo específico de enunciado: a expressão do pejorativo. Ex.: analfa.

(b) O truncamento reproduz parte da base e acrescenta uma vogal final $-a$, nem sempre presente na palavra-matriz. A vogal $-a$ funciona como uma espécie de afixo de truncamento. Ex.: estrangeiro $>$ estranja.

(c) A formação do truncamento não leva em conta o acento da base. Ex.: baterista > batera; flagrante > flagra.

(d) O truncamento é sempre paroxítono. 


\subsection{A abordagem de ARAÚJO (2002)}

Araújo (2002) apresenta uma análise mais aprofundada que a de Gonçalves (1999), em relação aos dois últimos pontos de sistematização levantados no tópico 2.1 (que dizem respeito à acentuação no processo de truncamento). De fato, visando à caracterização do truncamento como fenômeno regular e previsível, Araújo (2002) conclui que a forma truncada "tende a ser dissilábica e que o acento secundário representa papel crucial no processo". ${ }^{3}$ O autor divide as palavras truncadas em três grupos, sendo:

(2) (a) o das palavras truncadas dissílabas, formadas a partir de palavras-matriz trissilábicas com acento na penúltima sílaba (portanto, sem acento secundário) - Ex.: cerveja > cerva;

(b) o das palavras truncadas dissílabas provenientes de palavras-matriz com três ou mais sílabas e acento secundário - Ex.: bijuteria > biju;

(c) o das palavras truncadas trissilábicas - Ex.: salafrário > salafra.

Após analisar um conjunto de dados, Araújo (2002) estabelece que:

(3) (a) a palavra-matriz deve ter três ou mais sílabas;

(b) contando-se da esquerda para a direita, selecionam-se as duas primeiras sílabas da palavra e eliminam-se as restantes;

(c) as condições fonotáticas da língua devem ser respeitadas;

(d) o acento deve ser atribuído à sílaba que guardava acento secundário na palavra-matriz. Se não houver acento secundário, deve-se acentuar a penúltima sílaba.

São louváveis os esforços de Gonçalves (1999) e Araújo (2002), pois oferecem generalizações para a análise de fenômenos que até então eram tratados como idiossincráticos. Entretanto, embora pertinentes em alguns casos, os critérios apresentados pelos autores não foram suficientes para que analisássemos um conjunto de formas 
que coletamos em um experimento especificamente elaborado para avaliar o truncamento no PB. Em vários exemplos de nosso corpus, a palavra truncada não seguiu os critérios sugeridos por Gonçalves (1999) e Araújo (2002). Algumas questões decorrentes da análise das formas obtidas nesse experimento são abordadas a seguir. ${ }^{4}$

\section{UM EXPERIMENTO PARA AVALIAR O TRUNCAMENTO}

Esta seção apresenta alguns resultados de um experimento que realizamos com 59 alunos da Faculdade de Letras da UFMG, em 2004. Inicialmente convidamos os participantes a colaborar com a pesquisa e, nos casos de aceitação, foram apresentados aos colaboradores alguns exemplos de truncamento, como japonês > japa, analfabeto $>$ analfa, etc. Em seguida, pedimos que os participantes sugerissem formas truncadas para uma lista de vocábulos do português, tendo o cuidado de indicar o acento tônico da palavra truncada através do acento gráfico agudo. A tarefa foi realizada por escrito. As palavras matrizes selecionadas para o experimento foram aquelas cuja forma truncada observamos, em algum momento, no uso cotidiano dos falantes de Belo Horizonte. O nosso objetivo inicial era o de testar as regras estabelecidas por Araújo (2002), sobretudo no que diz respeito à tendência de se formarem truncamentos oxítonos (no caso das palavras-matriz portadoras de acento secundário). ${ }^{5}$ Tínhamos também o interesse de investigar a produtividade do truncamento. Segundo Gonçalves (1999), a palavra truncada deve ser sempre paroxítona. Contudo, em muitos casos, observamos que o índice de formação de truncamentos oxítonos foi bem maior que o de paroxítonos. Vejamos alguns exemplos: 
- Satisfação

TABELA 1

Número e percentual dos truncamentos possíveis para o vocábulo 'satisfação'

\begin{tabular}{l|c|c}
\hline Truncamento Sugerido & Número & Porcentagem \\
\hline Satísfa (trissílabo/paroxítono) & 30 & $54,5 \%$ \\
\hline Satís / Satí (dissílabo/oxítono) & 20 & $36,4 \%$ \\
\hline Sáti (dissílabo/paroxítono) & 3 & $5,5 \%$ \\
\hline Outros & 2 & $3,6 \%$ \\
\hline TOTAL & 55 & $100 \%$ \\
\hline
\end{tabular}

Como se viu, o índice de ocorrência dos truncamentos dissilábicos oxítonos (satís/sati 36,4\%) foi bem maior do que o percentual de sáti (5,5\%), dissílabo paroxítono. Vejamos mais um exemplo:

- Periferia

TABELA 2

Número e percentual dos truncamentos possíveis para o vocábulo 'periferia'

\begin{tabular}{l|c|c}
\hline Truncamento Sugerido & Número & Porcentagem \\
\hline Perí (dissílabo/oxítono) & 21 & $45,6 \%$ \\
\hline Perífa (trissílabo/paroxítono) & 17 & $37 \%$ \\
\hline Péri (dissílabo/paroxítono) & 4 & $8,7 \%$ \\
\hline Outros & 4 & $8,7 \%$ \\
\hline TOTAL & 46 & $100 \%$ \\
\hline
\end{tabular}

Também na tabela 2 , o percentual de ocorrência do dissilábico oxítono perí (45,6\%) é bem maior do que o de péri $(8,7 \%)$, dissílabo paroxítono. Em ambos os exemplos, chamou-nos a atenção o alto percentual de truncamentos trissilábicos (satisfa 54,5\% e perifa 37\%). De fato, para várias palavras do experimento, houve quem sugerisse um ou dois truncamentos trissílabos. Algumas sugestões foram: falsifi ( $<$ falsificado), celula ( $<$ celular), cafaja ( $<$ cafajeste), estrange, 
estrango e estranja (< estrangeiro), etc. A ocorrência de truncamentos trissílabos nos chamou a atenção, sobretudo porque esse tipo de truncamento parece ir de encontro à proposta de Araújo (2002), segundo a qual a tendência da língua é a de se formarem truncamentos dissilábicos.

Embora esses dados tenham um caráter experimental, os índices de ocorrência de truncamentos oxítonos e truncamentos trissilábicos indicam que estamos diante de um processo produtivo no PB. Observamos ainda propriedades importantes da vogal temática e do local do corte na palavra, bem como do rastreamento e acréscimo semântico nas palavras truncadas, que discutiremos na seção seguinte. Os dados que coletamos mostram que o truncamento é um processo que viabiliza várias possibilidades de formação de palavras. Assim, a partir da análise de nossos dados, verificamos que seria importante rever as análises precedentes. Esta é a proposta deste artigo, que tem por objetivo adicional indicar caminhos para análises futuras sobre o truncamento e a redução vocabular. Nas próximas seções, avaliamos as propostas de Gonçalves (1999) e Araújo (2002) à luz dos dados de nosso corpus e sugerimos algumas propostas para a análise de casos específicos.

\section{DISCUTINDO AS ANÁLISES DE GONÇALVES (1999) E ARAÚJO (2002)}

O primeiro aspecto que gostaríamos de comentar diz respeito a uma questão metodológica. Notamos que os trabalhos de Gonçalves (1999) e Araújo (2002) baseiam-se em poucos dados (o artigo de Gonçalves, por exemplo, apresenta apenas 19 dados). Visando a testar as generalizações oferecidas pelos autores, coletamos um corpus de 152 palavras truncadas e com redução vocabular e aplicamos os critérios estabelecidos por eles a tal corpus. Nosso corpus é apresentado ao final deste artigo. Ao fazê-lo, identificamos vários pontos controversos. São eles: 


\section{a) Vogal temática}

Começaremos discutindo a assertiva de Gonçalves (1999) sobre o fato de haver sempre a inserção de uma vogal final $-a$ no truncamento. De fato, há vários exemplos em que essa afirmação se comprova, sobretudo com os truncamentos trissilábicos (Exs.: telefone > telefa; vestibular > vestiba, etc.) Os dados de nosso corpus mostram que isso igualmente pode acontecer com os truncamentos dissilábicos (Exs.: burguês > burga; cruzeiro > cruza, etc.). Observe-se também que, nesses exemplos, a vogal final é realmente inserida, isto é, ela não constava da palavra-matriz. Há, porém, muitos truncamentos que não terminam com a vogal $-a$, mas numa vogal presente na palavra-matriz (Exs.: profissional $>$ profi; faculdade $>$ facu; rapaziada $>$ rapaze, etc.). Em nossa pesquisa, atestamos que, de um total de 47 truncamentos dissilábicos, 24 terminam em $-a$, e 23 terminam em outras vogais. Temos, portanto, um índice de quase 50\% de contra-exemplos à generalização proposta por Gonçalves (1999). Já para os truncamentos trissilábicos, a generalização da vogal final $-a$ pode valer como tendência, apesar de haver alguns contra-exemplos, como veremos mais adiante.

\section{b) Local do corte}

Outro ponto que gostaríamos de discutir é quanto ao local em que se dá o corte na palavra-matriz. Segundo Araújo (2002), a perda de material segmental se dá sempre "no limite direito da palavra". Entretanto, em nossos dados atestamos casos em que o corte ocorreu no limite esquerdo da palavra (Exs.: paranóia > nóia; cachaça > chaça; professor $>$ fessô). Observe-se que esse grupo de truncamentos parece apresentar um comportamento especial: o acento da palavramatriz é preservado na palavra truncada. Portanto, é típico, mas não obrigatório, que no truncamento haja mudança de acento na passagem da palavra-matriz para a palavra truncada. ${ }^{6}$ Por ora, deixaremos a questão desse grupo em aberto, uma vez que precisaríamos de mais dados para sugerir uma análise mais refinada. Contudo, uma 
análise ampla do truncamento e de fenômenos correlatos deverá levar em consideração esse grupo de palavras.

\section{c) O número de sílabas}

Uma outra questão a ser discutida é a do número de sílabas da palavra truncada. A tendência, segundo Araújo (2002), é a de que o truncamento seja dissilábico, apesar de o autor reconhecer que há casos de truncamentos trissilábicos. Cabem aqui duas observações. Primeiramente, não há apenas alguns casos de truncamentos trissilábicos. Em nossa pesquisa, observamos que esse tipo de truncamento corresponde a 42,0\% dos truncamentos prototípicos ${ }^{7}$, o que reflete um percentual bastante expressivo. Em segundo lugar, ao dizer que os truncamentos são predominantemente dissilábicos e, em alguns casos, trissilabos, Araújo (2002) não levanta a possibilidade de haver truncamentos monossilábicos. Observe-se, todavia, que no caso dos nomes próprios isso se verifica com bastante freqüência: Lu < Luciana, Luísa; Ju < Jussara, Juliana; Cris < Cristiane, Cristina; Fla $<$ Flamengo e Flu $<$ Fluminense, ${ }^{8}$ entre outros.

\section{d) Monossílabos}

Vale observar que a ocorrência de truncamentos monossilábicos parece ser válida apenas para os nomes próprios. Há evidência na literatura lingüística de que nomes próprios devem receber tratamento diferenciado (OLIVEIRA, 1995). Em substantivos comuns, a tendência é que a forma truncada apresente mais de uma sílaba. Um exemplo disso é o vocábulo busu (< ônibus), em que, além de o corte de material segmental ter se dado à esquerda, há o acréscimo da vogal $-u$, tornando dissilábico o monossílabo bus. Mais uma vez, lembramos que os nomes próprios configuram-se como casos especiais: eles podem ou não seguir a tendência geral dos truncamentos.

\section{e) Rastreamento}

Há ainda outra questão a ser considerada no trabalho de Araújo (2002). O autor coloca, como condição necessária à legitimidade do 
truncamento, o fato de a palavra-matriz ser sempre rastreável. Dessa forma, cerva seria um exemplo de truncamento por corresponder a uma única base - cerveja-, e deprê não o seria por poder corresponder tanto a depressão quanto a deprimido(a). Não vemos motivos para se excluir deprê do grupo dos truncamentos, tampouco outros casos como presí (< presidente ou presidiário?), socí (< social ou sociedade?), etc., em que a forma truncada pode corresponder a mais de uma palavra-matriz. Listaremos, mais adiante, as características de um truncamento prototípico, as quais se aplicam também a esse tipo de truncamento. Ademais, um truncamento que corresponda a mais de uma base será facilmente rastreável no contexto semântico-pragmático em que é proferido. Vejamos os mesmos exemplos que propõe Araújo (2002). A forma truncada deprê, numa frase como 'A deprê do João contagiou os colegas na empresa', só será rastreada como 'depressão', e nunca como 'deprimida'. Já em 'Joana está muito deprê depois da eliminação da filha do torneio', lê-se sempre 'deprimida', e nunca 'depressão'. Podemos supor, então, que não é o truncamento que apresenta duas palavras-matriz e sim palavras-matriz diferentes que geram truncamentos homônimos, mas que são sempre rastreáveis no contexto semântico-pragmático de proferimento.

\section{f) Acréscimo semântico9}

Preferindo se ater à formação estrutural das morfologias nãoconcatenativas, Araújo (2002) opta por não considerar o aspecto semântico envolvido nesses processos. Diz apenas que não há perda de sentido ao se passar da palavra-matriz para a truncada. Gonçalves (1999) faz a mesma afirmação, acrescentando, porém, uma observação: o truncamento é empregado com função expressiva, "revelando o ponto-de-vista do falante sobre o que se diz". A palavra truncada, apesar de conservar o sentido da palavra-matriz, serve para externar uma avaliação. Assim, analfa talvez externe uma avaliação negativa sobre o analfabeto.

Discordando de Gonçalves (1999) nesse ponto - para quem o truncamento expressa sempre o tom pejorativo -, pensamos que 
também o tom jocoso, o de zombaria, bem como o tom da afetividade e o da familiaridade, estão presentes nos diversos casos de truncamento de nosso corpus. Em refri (< refrigerante) e cerva (< cerveja), por exemplo, parece haver um tom familiar, de quem toma essas bebidas com freqüência; já em movi (< movimento) e rapaze (< rapaziada), um tom jocoso, e em motoca (< motocicleta), temos um tom afetivo. O truncamento poderia exercer também uma função "eufemística", como no caso da locução adjetiva do caralbo - considerada por muitos como um tabu lingüístico -, que é truncada para duca, que parece ser mais aceitável socialmente. Gonçalves (1999) e Araújo (2002) observam que o truncamento e fenômenos correlatos operam nos níveis fonológico e morfológico concomitantemente. Ambos reconhecem que o significado final da nova palavra também deveria ser levado em consideração, embora nenhum dos dois se proponha a tal investigação naquele momento. O nosso trabalho oferece evidências de que um tratamento completo dos referidos fenômenos deve levar em consideração não apenas os aspectos fonológico e morfológico, mas também a relação entre forma e significado que surge na nova palavra. Por ser um fenômeno típico da fala informal, o truncamento se presta com propriedade a um estudo que enfoque principalmente aspectos semântico-pragmáticos em consonância com parâmetros fonológicos e morfológicos. Tal estudo deve ainda ser desenvolvido em pesquisa futura, uma vez que neste artigo preferimos nos ater apenas aos aspectos estruturais do truncamento.

\section{REANALISANDO AS GENERALIZAÇÕES DE ARAÚJO (2002)}

Passemos à avaliação dos critérios impostos às palavras truncadas dissílabas provenientes de palavras-matriz com acento secundário. A fim de explicar a regularidade nos processos de truncamento, Araújo (2002) observa se há ou não acento secundário nas palavras-matriz e, a partir daí, classifica-as em dois grandes grupos. 


\section{Grupo 1: ARAÚJO (2002)}

(a) A palavra-matriz é trissílaba, paroxítona e não possui acento secundário.

Exs: neurose, flagrante.

(b) O truncamento é sempre dissílabo e paroxítono.

Exs.: neurose $>$ neura

flagrante $>$ flagra

Com relação ao acento, encontramos três exceções à regra proposta para o Grupo 1: fissu (< fissura), belê (< beleza) e pregui (< preguiça), que são formas truncadas oxítonas, e não paroxítonas. Portanto, a afirmativa apresentada por Araújo (2002) no Grupo1b parece indicar uma tendência, mas não um critério categórico. Encontramos ainda algumas palavras-matriz dissílabas e oxítonas gerando palavras truncadas dissílabas e paroxítonas (mesmo padrão das demais palavras truncadas do Grupo 1), fato que também contraria a regra apresentada no Grupola. Alguns exemplos de palavras-matriz dissílabas que geram truncamentos dissílabos são: chinês $>$ china), burguês $>$ burga, mulher $>$ mulha, tostão $>$ tusta, etc. Parece-nos necessário, portanto, rever o critério apresentado para o Grupo 1, ajustando-o de forma a englobar as palavras-matriz dissilábicas e os truncamentos oxítonos:

\section{Grupo 1: critério revisto neste trabalho}

A palavra-matriz pode ser dissílaba ou trissílaba, e há uma tendência a se formarem truncamentos paroxítonos.

Consideremos, agora, a proposta de Araújo (2002) para o Grupo 2 de truncamentos: 


\section{Grupo 2: ARAÚJO (2002)}

(a) A palavra-matriz é trissilaba ou polissílaba e possui acento secundário (o acento grave marca a sílaba portadora de acento secundário).

Exs.: jàponês, bijùteria

(b) O truncamento é sempre dissílabo, e o acento é sempre atribuído à sílaba que guardava o acento secundário.

Exs.: jàponês $>$ japa

bijùteria $>$ biju

Estabelece-se, portanto, uma relação obrigatória entre o truncamento e o acento secundário nesse grupo. Tal relação, contudo, não se verifica em pelo menos 15 (47,0\%) das 32 palavras que analisamos. ${ }^{10}$ Alguns exemplos de truncamento que violam os critérios para o Grupo 2 apresentado anteriormente são mostrados a seguir. Neles, indicamos a sílaba tônica em itálico:

\begin{tabular}{|l|}
\hline Dèpressão - que gera deprê, e não, depre; \\
\hline Fàculdade - que gera facu, e não, facu; \\
\hline Càchoeira - que gera cachu, e não, cachu; \\
\hline Prèju ízo - que gera preju, e não, preju; \\
\hline Mòrdomia - que gera mordô, e não, mondo. \\
\hline
\end{tabular}

Note-se que, nesses exemplos, o acento da nova palavra não corresponde ao acento secundário da palavra-matriz. Tendo em vista esses dados, nossa hipótese é que a relação entre acento secundário e palavras truncadas provenientes especificamente desse grupo pode ser acidental. O que realmente há é uma tendência a se formarem truncamentos oxítonos, quando a palavra-matriz possui acento secundário. Em nossa pesquisa, tivemos um índice de 65,6\% (21/32) de casos de truncamentos oxítonos nesse grupo, contra apenas 34,4\% (11/32) de ocorrências de formas truncadas paroxítonas. ${ }^{11}$ 


\section{Grupo 2: critério revisto neste trabalho}

Para palavras-matriz contendo acento secundário, o truncamento, se dissílabo, é preferencialmente oxítono.

Resta-nos falar dos truncamentos trissilábicos, que formam um grupo à parte. Para esses casos, Araújo (2002) não especifica nenhum traço para a palavra-matriz, indicando apenas que os truncamentos desse grupo são sempre paroxítonos, com vogal temática $-a$.

\section{Grupo 3: ARAÚJO (2002)}

(a) Não há traços para a palavra-matriz.

Exs.: jàponês, bijùteria

(b) O truncamento é trissílabo e sempre paroxítono, com vogal temática $-a$.

Exs.: periferia $>$ perifa

madrugada $>$ madruga

Com relação ao acento tônico, não encontramos nenhum caso que contradissesse o critério estabelecido por Araújo (2002): todos os truncamentos desse grupo são paroxítonos. Entretanto, observamos casos de truncamentos como boteco (< botequim), que curiosamente termina em $-o$, e rapaze (< rapaziada), que termina em $-e$. Parece, então, que nesse grupo a vogal final é preferencialmente, mas nem sempre, $-a$. Assim, podemos incluir aí os truncamentos boteco e rapaze.

\section{Grupo 3: critério revisto neste trabalho \\ O truncamento trissílabo é sempre paroxítono e a vogal final é preferencialmente $-a$.}

Nesta seção apresentamos alguns pontos controversos nas análises do truncamento apresentadas por Araújo (2002). Avaliamos as propostas do autor e sugerimos critérios adicionais para a análise 
do truncamento no PB. Nossas sugestões seguiram da análise dos dados presentes em nosso corpus.

Na próxima seção apresentamos uma proposta de distinção entre truncamento e redução vocabular.

\section{TRUNCAMENTO E REDUÇÃO VOCABULAR}

Falaremos agora da distinção entre truncamento e redução vocabular, processos muitas vezes confundidos e analisados como idênticos. Alguém poderia pensar que motoconstitui um exemplo típico de truncamento, e isso é o que de fato vemos acontecer nas gramáticas e manuais de morfologia de um modo geral. Entretanto, analisando os dados de nosso corpus, notamos que existem características que nos permitem relacionar a forma moto ao processo da redução vocabular, e não ao do truncamento. Mostramos, a seguir, uma tentativa de distinção desses processos.

A redução vocabular parece se diferenciar do truncamento por ser, essencialmente, um fenômeno morfológico, e não morfofonológico. O local onde se dá o corte na palavra que sofre redução é um limite morfológico. As palavras-matriz das reduções vocabulares são palavras compostas (que podem ser grafadas com hífen ou não), e é justamente no limite dessa composição que elas sofrem a redução. (Exs.: fotografia [foto+grafia] > foto; retro-projetor [retro+projetor] > retro; lipoaspiração [lipo+aspiração] > lipo). A forma resultante do processo de redução vocabular é uma das bases da palavra composta, em geral, a base que se encontra no limite esquerdo da palavra, ${ }^{12}$ que passa a ser empregada no lugar da palavra composta. Resumindo, a redução vocabular é um corte morfológico, que desfaz a composição que deu origem à palavra-matriz. Pode-se dizer que há uma forte tendência a se manterem as bases à esquerda da palavra-matriz. Além disso, na redução vocabular, não há inserção da vogal final - $a$, o que ocorre com bastante freqüência no truncamento.

Nos casos de truncamento, as palavras-matriz não são, em geral, compostas. Contudo, mesmo quando há uma palavra-matriz 
composta, o corte que ocorre no truncamento não é um corte morfológico, como acontece na redução vocabular (Exs.: grã-fino > granfa; mal-criado > malcra). No caso da matriz play-boy, por exemplo, temos duas possibilidades de "corte": pleiba e play; a primeira delas é um truncamento (atente-se para a inserção da vogal final $-a$ ), enquanto a segunda é uma redução vocabular (o corte se dá na morfologia).

Outro ponto interessante da distinção entre truncamento e redução vocabular é o aspecto semântico-pragmático. O truncamento, como vimos, é usado na expressão do pejorativo, do jocoso e do afetivo, ao passo que a redução vocabular parece ter propriedades semânticas mais neutras, expressando apenas uma certa intimidade com o tema ao qual a palavra reduzida se refere. O truncamento possui traços de gíria, de linguagem socialmente marcada, específica de determinado grupo social (sobretudo o grupo de faixa etária mais jovem); a redução vocabular parece não externar tal marcação, podendo ser usada por todos os grupos sociais.

\section{CONCLUSÃO}

Neste artigo, avaliamos o fenômeno do truncamento, tomando como ponto de partida as descrições encontradas nos manuais tradicionais de morfologia e em trabalhos como os de Gonçalves (1999) e Araújo (2002). Após apresentarmos uma revisão da literatura, fizemos uma leitura crítica das análises correntes, discutindo aspectos controversos, propondo uma reanálise das generalizações disponíveis e sugerindo outros pontos a serem investigados em trabalhos futuros.

A partir das observações que fizemos ao longo deste artigo, gostaríamos de formular a noção de truncamento a partir de tendências gerais e não categóricas. O principal aspecto estrutural do truncamento é (a) a conjugação de aspectos fonológicos e morfológicos na concepção de um novo vocábulo que apresenta marcas sociais importantes como a 'intimidade' ou 'familiaridade' no uso da palavra truncada e (b) o fato de os truncamentos serem 
atestados predominantemente no grupo de faixa etária mais jovem. Retomamos a seguir os principais pontos avaliados neste artigo, que indicam as tendências observadas nos casos de truncamento analisados.

Observamos, por exemplo, que a palavra truncada preserva o sentido da palavra-matriz, mas acrescenta a ele uma carga expressiva de intimidade ou familiaridade (pejorativa, jocosa, afetiva ou familiar) que é observada no uso da palavra truncada em contexto semânticopragmático específico. Notamos que, nos truncamentos dissilábicos, pode-se manter uma vogal presente na palavra-matriz (cafajeste > cafa; visual $>$ visu) ou pode-se inserir uma vogal final $-a$, mesmo que essa não esteja presente na matriz (burguês > burga). Já nos truncamentos trissílabos, vimos que a tendência é mesmo a inserção da vogal final $-a$, apesar de haver a possibilidade de se usarem outras vogais finais (botequim > boteco). Mostramos que a perda de material segmental pode se dar tanto no limite direito (cachaça > chaça), quanto no limite esquerdo (neurose $>$ neura) da palavra-matriz, mas que a tendência é que ela ocorra no limite direito. Apontamos para a alta incidência de truncamentos trissilábicos em nosso corpuse para o fato de os substantivos comuns não gerarem, preferencialmente, truncamentos monossilábicos (exceção para os nomes próprios: Cristina, Cristiane $>$ Cris; Luciana $>$ Lu). Discutimos a questão da existência de duas ou mais palavras-matriz para uma mesma forma truncada e mostramos que, nesses casos, a palavra-matriz pode ser sempre recuperada no contexto semântico-pragmático (deprimida, depressão > deprê ). No que diz respeito à relação entre acento secundário e palavra truncada, mostramos que, no caso do primeiro grupo (i.e., palavras-matriz sem acento secundário), a palavra-matriz também pode ser dissílaba (chinês > china) e que há uma tendência a se formarem truncamentos paroxítonos (neurose $>$ neura). Para as palavras-matriz portadoras de acento secundário, a tendência é que gerem truncamentos oxítonos, quando esses forem dissílabos (movimento $>$ movi). No caso dos truncamentos trissilábicos, vimos que são sempre paroxítonos e que terminam preferencialmente, mas nem sempre, em $-a$ (telefone > telefa; botequim > boteco). Verificamos que, em alguns casos de truncamento, há inserção de segmentos não 
constantes na palavra-matriz. É o caso de tranqüilo $>$ tranquis, pirralho/a $>$ pirras, ônibus $>$ busu, etc. Sugerimos, por fim, critérios para a distinção entre truncamento e redução vocabular.

Os resultados apresentados e descritos neste trabalho podem contribuir para uma melhor compreensão do processo de formação de palavras, ou de ampliação do léxico no PB. Embora se trate de resultados preliminares, podemos afirmar que o léxico tem caráter produtivo e tende a seguir os critérios estruturais da língua em questão. A produtividade da criação lexical, alinhada à variação inerente a tal processo de criação, sugere uma concepção de léxico como um sistema com plasticidade que se adapta às necessidades dos falantes (LORD \& ZUNG, 1992). A teoria que sugere tal proposta é a da "Difusão Lexical" (WANG, 1969), que poderia ser considerada em trabalhos futuros sobre o truncamento. Tal teoria sugere que a palavra é a unidade representacional na estrutura lingüística e permite-nos inseri-la num contexto semântico-pragmático que seja relevante para a análise lingüística.

Enfim, acreditamos que este trabalho expresse a necessidade de estudos futuros de cunho sociolingüístico e semântico-pragmático, que busquem uma avaliação dinâmica e contextualizada do léxico na organização da linguagem com enfoque no truncamento e na redução vocabular no português brasileiro.

\section{NOTAS}

${ }^{1}$ As autoras agradecem os comentários e sugestões dos pareceristas anônimos da revista.

${ }^{2}$ A autora agradece o apoio do CNPq - Conselho Nacional de Desenvolvimento Científico e Tecnológico, através do processo 30.41.21-2002-9.

${ }^{3}$ Para simplificar, usaremos caracteres itálicos para indicar a sílaba tônica e o acento grave, quando necessário, para marcar a posição do acento secundário (COLLISCHON, 1994).

${ }^{4}$ Alguns dados de nosso experimento são brevemente descritos na próxima seção. O corpus completo é apresentado no Anexo, que se encontra ao final do artigo. 
${ }^{5}$ Este trabalho iniciou-se a partir de discussões sobre o tema que surgiram em disciplinas específicas ministradas pelas professoras Thaïs Cristófaro Silva e Ana Paula Huback na Faculdade de Letras da UFMG. Posteriormente, a partir das reflexões sobre o tema, selecionamos as palavras a serem testadas e aplicamos o experimento.

6 Trask (1996) sugere que, nos casos de truncamento, o corte se dê sistematicamente no limite direito da palavra. Contudo, tal restrição não é observada por Crystal (2001). Assumimos que o truncamento diz respeito ao encurtamento da palavra, sem restrições à borda - esquerda ou direita - em que o corte segmental possa ocorrer.

7 Por truncamento prototípico estamos nos referindo aos casos em que a palavra-matriz não é um nome próprio, nem há acréscimo de segmento à palavra truncada. Esses últimos casos, especiais, serão discutidos mais adiante.

${ }^{8}$ Os itens Fla e Flu são normalmente empregados em justaposição, para designar o clássico jogo entre os referidos times (cf. FlaFlu).

${ }^{9}$ Não faremos aqui uma distinção rígida entre o que está no âmbito da semântica e o que está no âmbito da pragmática. Chamaremos de questões "semânticas" tudo o que disser respeito ao significado, num sentido amplo, no fenômeno do truncamento.

${ }^{10}$ Considerando, naturalmente, apenas os truncamentos prototípicos.

${ }^{11}$ Vide a segunda coluna do corpus anexo, relativa aos dados do Grupo 2.

${ }^{12}$ Encontramos apenas um contra-exemplo: teipe, de 'videoteipe'. Possivelmente, a redução vocabular vídeo já havia sido formulada para 'videocassete'.

\section{REFERÊNCIAS BIBLIOGRÁFICAS}

ARAÚJO, Gabriel. Truncamento e reduplicação no português brasileiro. Revista de Estudos da Linguagem. Belo Horizonte, v.10, n.1, p. 61-90, jan./jun. 2002.

BASíliO, Margarida. Teoria lexical. 3. ed. São Paulo: Ática, 1991. (Série Princípios) BECHARA, Evanildo. Moderna Gramática Portuguesa. 37. ed. rev. e ampl. Rio de Janeiro: Lucerna, 2001.

COLLISCHON, Gisela. Acento secundário em português. Letras de hoje. Porto Alegre, v. 29, no. 4, p. 43-53, dez. 1994.

CEGAllA, Domingos Paschoal. Minigramática da lingua portuguesa. São Paulo: Companhia Editora Nacional, 1991. 
CRYSTAL, D. A Dictionary of Linguistics and Phonetics. Blackwell, 2001.

CUNHA, Celso; CINTRA, Luis F. Lindley. Nova gramática do português contemporâneo. Rio de Janeiro: Nova Fronteira, 1985.

GONÇALVES, Carlos Alexandre. Processos Morfológicos Não-Concatenativos no português do Brasil: tipos e funções. [Versão revista e ampliada da Comunicação "Processos de redução vocabular: tipos e funções", apresentada na XVII Jornada de Estudos Lingüisticos do GELNE, Recife, Instituto de Letras da UFPE, set. 1999.

LORD \& ZUNG. How does the lexicon work? Word. v. 43, n.3, p. 349-373, 1992. LUFT, Celso Pedro et al. Novo manual de português, gramática, ortografia oficial, literatura, redação, textos e testes. São Paulo: Globo, 1996.

OLIVEIRA, M. A. O léxico como controlador de mudanças sonoras. Revista de Estudos da Linguagem. Belo Horizonte, Faculdade de Letras da UFMG, p. 75-92, 1995.

ROCHA, L. C. A. Estruturas morfológicas do português. Belo Horizonte: Editora UFMG, 1999. (Coleção Aprender)

SANDMANN, A. Morfologia lexical. São Paulo: Contexto, 1992. (Coleção Repensando a Língua Portuguesa)

TRASK, R. L. A Dictionary of Phonetics and Phonology. Routledge, 1996.

WANG, W. Competing changes as a cause of residues. Language. 45, n.1, p. 9-25, 1969. 


\begin{tabular}{|c|c|c|c|c|}
\hline $\begin{array}{l}\text { Truncamentos } \\
\text { dissilábicos } \\
\text { (sem ac. secund) }\end{array}$ & $\begin{array}{l}\text { Truncamentos } \\
\text { dissilábicos } \mathbf{2} \\
\text { (com ac. secund) }\end{array}$ & $\begin{array}{l}\text { Truncamentos } \\
\text { trissilábicos }\end{array}$ & $\begin{array}{l}\text { Truncamentos com } \\
\text { corte à esquerda }\end{array}$ & Redução vocabular \\
\hline $\begin{array}{l}\text { Belê (beleza) } \\
\text { Berma (bermuda) } \\
\text { Burga (burguês) } \\
\text { Cerva (cerveja) } \\
\text { China (chinês) } \\
\text { Cruza (cruzeiro) } \\
\text { Demo (demônio) } \\
\text { Fissu (fissura) } \\
\text { Flagra (flagrante) } \\
\text { Frila (freelance) } \\
\text { Granfa (grã-fino) } \\
\text { Milha (milhão) } \\
\text { Mulha (mulher) } \\
\text { Neura (neurose) } \\
\text { Palha (palhaço) } \\
\text { Pisça (piscina) } \\
\text { Playba (playboy) } \\
\text { Pregui (preguiça) } \\
\text { Purfa (por fora) } \\
\text { Sarja (sargento) } \\
\text { Tusta (tostão) } \\
\text { Nomes-próprios: } \\
\text { Brasa (Brasil) } \\
\text { Sampa (São Paulo) }\end{array}$ & $\begin{array}{l}\text { Biju (bijuteria) } \\
\text { Bisa (bisavó) } \\
\text { Cafa (cafajeste) } \\
\text { Carna (carnaval) } \\
\text { Coca (cocaína) } \\
\text { Confa (confusão) } \\
\text { Dispô (disposição) } \\
\text { Facu (faculdade) } \\
\text { Falsi (falsificado) } \\
\text { Jabá (jabaculê) } \\
\text { Japa (japonês) } \\
\text { Loto (loteria) } \\
\text { Metal (metaleiro) } \\
\text { Mordô (mordomia) } \\
\text { Preju (prejuízo) } \\
\text { Profi (profissional) } \\
\text { Refri (refrigerante) } \\
\text { Sapa (sapatão) } \\
\text { Transa (transação) } \\
\text { Trava (travesti) } \\
\text { Troglô (troglodita) } \\
\text { Biju (bijuteria) } \\
\text { Bisa (bisavó) } \\
\text { Cafa (cafajeste) } \\
\text { Carna (carnaval) } \\
\text { Coca (cocaína) } \\
\text { Confa (confusão) } \\
\text { Dispô (disposição) } \\
\text { Facu (faculdade) } \\
\text { Sacrista (sacristão) } \\
\text { Salafra (salafrário) }\end{array}$ & $\begin{array}{l}\text { Adrena (adrenalina) } \\
\text { Analfa (analfabeto) } \\
\text { Balanta (ballantines) } \\
\text { Balzaca (balzaquiana) } \\
\text { Batera (bateria, baterista) } \\
\text { Boteco (botequim) } \\
\text { Cacete (cacetete) } \\
\text { Cafeta (cafetão) } \\
\text { Capita (capitão) } \\
\text { Carpina (carpinteiro) } \\
\text { Catega (categoria) } \\
\text { Celula (celular) } \\
\text { Cesária (cesariana) } \\
\text { Comissa } 1 \text { (comissão, } \\
\text { comissário) } \\
\text { Comuna (comunista) } \\
\text { Consuma (consumação) } \\
\text { Cortesa (cortesia) } \\
\text { Delega } 1 \text { (delegado, delegacia) } \\
\text { Estranja (estrangeiro) } \\
\text { Madruga (madrugada) } \\
\text { Maneca (manequim) } \\
\text { Motoca (motocicleta) } \\
\text { Natura (natureza) } \\
\text { Perifa (periferia) } \\
\text { Portuga (português) } \\
\text { Proleta (proletariado) } \\
\text { Rapaze (rapaziada) } \\
\text { Reaça (reação) } \\
\text { Responsa (responsabilidade) }\end{array}$ & $\begin{array}{l}\text { Chaça (cachaça) } \\
\text { Fessô (professor) } \\
\text { Nóia (paranóia) } \\
\text { Nomes Próprios: } \\
\text { Mengo (Flamengo) } \\
\text { Zêro (Cruzeiro) } \\
\text { Acréscimo de segmento: } \\
\text { Busu (ônibus) }\end{array}$ & $\begin{array}{l}\text { Bíblio (Biblioteconomia) } \\
\text { Curta (curta-metragem) } \\
\text { Eletro (eletrocardiograma) } \\
\text { Espéleo (espeleologia) } \\
\text { Ex (ex-marido; ex-namorado...) } \\
\text { Extra (extraordinário) } \\
\text { Foto (fotografia) } \\
\text { Hétero (heterossexual) } \\
\text { Hidro (hidroginástica) } \\
\text { Homo (homossexual) } \\
\text { Infra (infraestrutura) } \\
\text { Inter (Internacional) } \\
\text { Lipo (lipoaspiração) } \\
\text { Longa (longa-metragem) } \\
\text { Maxi (maximização) } \\
\text { Micro (microcomputador) } \\
\text { Mini (minissaia) } \\
\text { Moto (motocicleta) } \\
\text { Odonto (odontologia) } \\
\text { Otorrino (Otorrinolaringologista) } \\
\text { Over (overnight) } \\
\text { Play (playboy) } \\
\text { Pólio (poliomielite) } \\
\text { Pornô (pornográfico) } \\
\text { Pós (pós-operatório; } \\
\text { pós-graduação) } \\
\text { Pré (pré-vestibular; } \\
\text { pré-operatório; pré-primário) } \\
\text { Quilo (quilograma) } \\
\text { Químio (quimioterapia) } \\
\text { Rádio (radioterapia) } \\
\text { Retro (retroprojetor) } \\
\text { Vice (vice-presidente; } \\
\text { vice-governador...) }\end{array}$ \\
\hline
\end{tabular}




\begin{tabular}{|l|l|l|l|l|}
\hline $\begin{array}{l}\text { Truncamento } \\
\text { dissilábicos } \\
\text { (sem ac. secund) }\end{array}$ & $\begin{array}{l}\text { Truncamento } \\
\text { dissilábicos 2 } \\
\text { (com ac. secund) }\end{array}$ & $\begin{array}{l}\text { Truncamento } \\
\text { trissilábicos }\end{array}$ & $\begin{array}{l}\text { Truncamento com } \\
\text { corte à esquerda }\end{array}$ & Redução vocabular \\
\hline $\begin{array}{l}\text { Japa (japonês) } \\
\text { Loto (loteria) }\end{array}$ & $\begin{array}{l}\text { Sanducha (sanduíche) } \\
\text { Sapata (sapatão) } \\
\text { Satisfa (satisfação) }\end{array}$ & Nomes próprios: & Telefa (telefone) & Corte à esquerda: \\
& Telôpe (videoteipe)
\end{tabular}

